\title{
How adrenal fatigue from chronic stress affects your health
}

\section{Opinion}

Perfectionists and self-slave drivers beware: are you still feeling tired even after seemingly energy-boosting activities such as sleeping or exercise and you can't quite put a finger to what's causing it? Alternative medicine has an explanation.

Adrenal fatigue refers to a cluster of symptoms that appear when your adrenal glands function below par as a result of high levels of stress suffered over the long term.

Just how important are the adrenals and why should we worry if they don't function well? The adrenal glands play a big role in delivering the morning jolt of energy you need to get yourself out of bed and then keep you awake, alert and focused for the rest of the day.

They also release hormones such as adrenaline and cortisols which help our body cope with stress. When the body goes through too much stress, for too long, the adrenal glands inevitably get exhausted from sustaining too much stress hormones and its functioning declines.

When this happens, an over-all feeling of exhaustion appears as well as the following:

a) Poor stamina

b) Tiredness after exercise

c) Inability to fall asleep, poor sleep quality and difficulty getting out of bed

d) Difficulty concentrating

e) Depression and anxiety

f) Irregular menstrual cycle

g) Stiff and achy joints and muscles

h) Bloating and poor digestion

i) Food cravings and abnormal weight gain in the midsection

j) Weak immune system

Little wonder this condition is called "The $21^{\text {st }}$ century stress syndrome" because its sufferers are those who get little rest and not enough relaxation, continually pushing themselves to their physical and mental limits. Also vulnerable are people who are going through grave emotional trauma, are seriously ill or seeing how a loved one suffers because of the same.
Volume 5 Issue 3 - 2016

\author{
Susan Meyer \\ CIM President, Canada
}

Correspondence: Susan Meyer, CIM President, 2824I Crown Valley Parkway, Suite F-4I 5 Laguna Niguel, CA 92677, Canada, Tel I888708SLIM (7546), Fax I8663733094,

Email smeyer@cortislim.com

Received:September 27, 2016 | Published: November 15, 2016

Anyone from any gender, race or social class can be vulnerable, from the political leader continually parrying attacks on his job and on his person, to the university student cramming with exams and projects, to the villager always on the lookout in a war-torn region, even a single mother on the job by day and taking care of young children at night. All of them lead different lifestyles, but one thing binds them in common: being overwhelmed with too many responsibilities and having too little time to indulge in enjoyable and rejuvenating activities.

So what can be done to correct adrenal imbalances and counteract the toxic results of chronic stress? The answer is quite simple, and what we should have been doing all along-striking a balance between wearing your superhero cape and being plain Jane or John enjoying the beauty of a sunrise and stopping to admire the colourful flowers you pass by.

That's right, just slowing down can do a lot to restore your body's natural defences. There's no need for expensive treatments and grand holidays either. Reduce your workload to a tolerable level, just say NO if you feel overwhelmed, and make sure to have the following daily: exercise, meditation, enough sleep, and a healthy, balanced diet. Dietary supplements, like CortiSLIM that compliment your lifestyle can be beneficial for stress and weight management.

\section{Acknowledgements}

None.

\section{Conflict of interest}

The author declares no conflict of interest. 